\title{
Gerusan Lokal yang Terjadi di Hilir Bendung dan Upaya Pengendaliannya
}

\author{
Lokal Scourat at The End Side of Dam Construction \\ and Its Preventive Works
}

\begin{abstract}
Wisafri
Jurusan Teknik Sipil Politeknik Negeri Padang Kampus Limau Manis Padang Telp.0751-72590 Fax.0751-72576 Email: wisafrikoto@yahoo.co.id
\end{abstract}

\begin{abstract}
Majarity of damages on the dam construction in Indonesia is caused by continuous local scouring at the end side of the dam construction. It grows and reach its lower/bottorm part. It could results in degradation in the dam operation safety. This local scouring was caused by major water flowing passing the dam where there is a high difference level between the top and the end of the dam. Furthermore, it generates inbalancing water flow speed and additional water turbulence. There are different approachs to prevent such damage, and for example by providing one or more additional construction at the end part of the dam. This structure is designed and installed at the bottom part of the dam. Various empirical functions have been developed to design this structure, and one of them is developed by Lacey. The function is reprsented by $D=0.47 *(Q / F)^{1 / 2}(\mathrm{D}=$ scouring depth, $\mathrm{Q}=$ Discharge, $F=$ the size of the sand particle). However, that function has some limitation. For examples are the local river and dam construction characteristics. Therefore, it is required to be validated by developing a model of dam contructed in a laboratory. Experiments was undertaken by using the model with different characteristics of water flow in order to investigate the scouring pattern, and than method prefentif work
\end{abstract}

Keywords : local scouring, dam, preventive work

\section{PENDAHULUAN}

Negara Republik Indonesia sebagian besar rakyatnya masih bermata pencaharian di bidang pertanian (agraris). Dengan kondisi tersebut secara tidak langsung mengakibatkan pemerintah harus mengembangkan jaringan irigasi teknis secara besar-besaran untuk mengairi areal pertanian yang ada sekarang dan untuk kebutuhan di masa datang. Maka untuk memenuhi kebutuhan suplai air tersebut telah dibangun cukup banyak bangunanbangunan hidraulik seperti bendung, embung, waduk, chek dam dan lain-lain.

Bendung adalah bangunan yang melintang disungai/saluran yang berfungsi untuk menaikkan elevasi muka air dari sungai yang dibendung sampai kepada taraf tertentu, sehingga air yang dibendung dapat mengalir secara aliran gravitasi sampai ke areal pertanian yang akan diairi. Bagianbagian dari bendung antara lain: tubuh bendung (terdiri dari mercu dan kolam olakan), lantai depan, lantai belakang, tembok sayap (depan dan belakang), bangunan penangkap sedimen, saluran pembilas dan sebagainya. Berdasarkan fungsi bendung untuk menaikkan muka air, akan menyebabkan perbedaan elevasi muka air antara hulu dan hilir bendung menjadi tinggi. Perbedaan elevasi ini akan menimbulkan limpasan atau terjunan yang mempunyai energi besar dan kecepatan yang lebih tinggi dari aslinya, sehingga mengganggu keseimbangan aliran.

Konsentrasi kecepatan jatuh aliran yang besar dengan gradien tekanan ke tanah yang abnormal, serta turbulensi aliran akan menyebabkan peluang besar terjadi erosi. Aliran super kritis yang melimpas dari 
spillway akan menyebabkan terjadinya profil loncatan hidraulik (hydraulic jump) dan hal ini akan mempengaruhi juga besarnya penggerusan setempat dihilir bendung. Gejala yang terjadi pada kaki bendung dengan hanyutnya material dasar sungai tersebut dikenal dengan gejala penggerusan setempat (Local Scouring). Penggerusan setempat serta terjadinya rembesan (seepage) dari hulu ke hilir tubuh bendung, sehingga secara keseluruhan mengurangi kestabilan struktur bendung.

\section{METODOLOGI}

\section{Pemodelan Fisik Dua Dimensi}

Untuk mendisain suatu kontruksi pengendali erosi suatu bendung, para ahli rancang rekayasa (insinyur) akan berhadapan dengan sejumlah variabel disamping variabel keadaan arus itu sendiri. Karena adanya hubunganhubungan dari berbagai variabel tersebut, sulit untuk melakukan standarisasi desain lantai spillway atau menjamin dicapainya hasil memuaskan dengan cara mengasumsikan sama dengan struktur yang sudah ada.

Walaupun banyak proses aliran yang dapat ditelusuri pada tingkat teoritisnya, masih banyak hubungan dengan variabel-variabel yang rumit. Melalui pendekatan persamaan matematis atau persamaan differensial sering kali tidak menyelesaikan masalah dan tidak sesuai dengan kenyataan di lapangan. Selain itu perkembangan proses penggerusan di hilir bangunan spillway juga hampir tidak dapat dihitung secara teoritis. Penyelidikan uji model fisik karena itu merupakan alternatif terbaik untuk memahami proses penggerusan, serta menguji parameter parameter yang diperlukan untuk melindungi dasar sungai dari proses deformasi yang terjadi. Oleh karena itu model test ini sangat relevan untuk mempelajari mekanisme penggerusan, karena informasi perubahan interaksi antara dasar sungai yang berdeformasi dan aliran air dapat ditentukan secara langsung. Penggerusan yang terjadi relatif dekat ke struktur hidraulik akan mempengaruhi stabilitasnya dan merupakan masalah keamanan yang serius. Dari berkali kali pengujian model fisik tiga dimensi yang telah dilakukan, hasilnya yang terbaik akan dijadikan sebagai acuan untuk pengujian model fisik tiga dimensi yang disesuaikan dengan rancangan akhir dari prototipe.

Hal yang perlu diperhatikan dalam membuat sebuah pemodelan fisik adalah harus sesuai dengan kondisi prototipenya. Dengan demikian sifat-sifat model diharapkan akan mewakili sifat-sifat prototipenya. Dalam menentukan skala model fisik hidraulik, beberapa hal yang harus dipertimbangkan adalah : Ruang laboratorium yang tersedia,

Suplai air dan Ketersediaan waktu .

\section{Pelaksanaan Penelitian}

Sebagaimana telah dijelaskan sebelumnya bahwa penelitian dilakukan pada saluran terbuka berdinding akrilik dengan lebar 0,40 $\mathrm{m}$ sepanjang 3 (tiga) meter. Saluran tersebut terdapat pada ruang Laboratorium Uji Model Hidraulik (Laboratorium Hidraulika) Jurusan Teknik Sipil, Politeknik Negeri Padang.

Langkah pertama pelaksanaan penelitian yang dilakukan adalah pengecekan terhadap indeks dari meteran taraf diatas permukaan Spillway dan di dasar pintu Thompson, agar di saat pengukuran tidak terjadi kesalahan dalam pembacaan angka pada meteran taraf.

Kemudian pasir yang telah disaring dengan kawat harmonika ukuran kecil lalu dihamparkan pada dasar saluran terbuka di hilir Spillway setebal tinggi ujung akhir dari Bucket sampai rata dan padat. Pemadatan pasir dilakukan dengan alat pemadat yang terbuat dari balok kayu, 
kemudian air dialirkan pada saluran tersebut selama kurang lebih 1(satu) jam agar menjadi padat, setelah itu pompa dimatikan dan siap dikeringkan.

\section{Mengukur Kedalaman Aliran di Saluran}

Untuk mengukur kedalaman aliran di saluran dilakukan dengan alat ukur meteran taraf yang berada di atas dan di hilir Spillway. Setelah permukaan pasir di hilir bendung dihamparkan dan diratakan selanjutnya didapatkan perbedaan antara elevasi mercu dengan elevasi permukaan pasir, maka air kemudian dialirkan dengan debit-debit yang telah ditentukan dalam waktu 2 jam sampai 3 jam. Pengukuran kedalaman aliran dapat dilakukan bila debit sudah konstan, yaitu bila pengukuran meteran taraf di kedalaman hulu bendung tidak berubah-rubah lagi, biasanya terjadi setelah air dialirkan setelah 1 jam. Kemudian dilakukan pengukuran kedalaman air di atas Spillway, kedalaman pada awal loncatan air, kedalaman loncatan air maksimum, dan panjang loncatan air di hilir Spillway, serta kedalaman air normal hilir

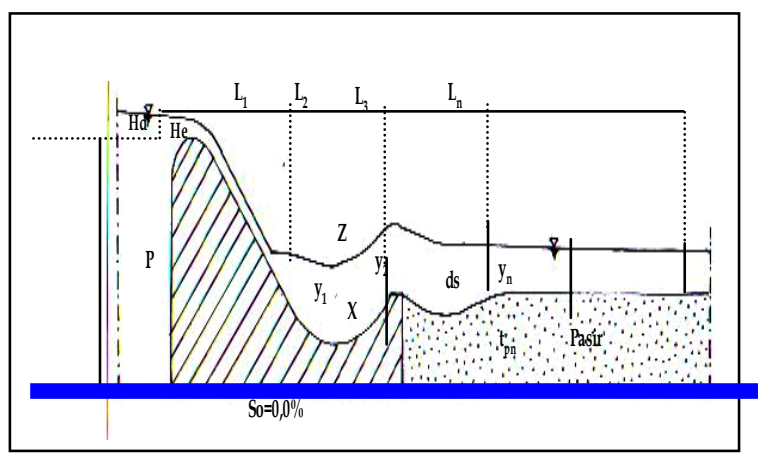

Gambar 1. Definisi dan simbol bendung dengan peredam energy tipe Bucket tunggal.

Dari gambar di atas, pengukuran kedalaman air tersebut dilakukan untuk mendapatkan :
- Kedalaman aliran (Hd) sebelum melewati Spillway.

- Kedalaman aliran (He) yang berada tepat dipuncak Spillway

- Kedalaman aliran $\left(\mathrm{y}_{1}\right)$ di awal loncatan.

- Kedalaman aliran $\left(\mathrm{y}_{2}\right)$ permukaan aliran sudah mulai naik.

- Kedalaman aliran $\left(\mathrm{y}_{\mathrm{n}}\right)$ permukaan air hilir.

- Panjang loncatan air $\left(\mathrm{L}_{1}\right)=$ jarak antara as bendung ke lokasi permukaan air mulai jatuh.

- Panjang loncatan air $\left(\mathrm{L}_{2}\right)=$ jarak antara permukaan air mulai jatuh ke $\mathrm{y}_{1}$.

- Panjang loncatan air $\left(\mathrm{L}_{3}\right)=$ jarak antara $\mathrm{y}_{1}$ ke $\mathrm{y}_{2}$.

- Panjang loncatan air $\left(\mathrm{L}_{\mathrm{n}}\right)=$ jarak antara $\mathrm{y}_{2}$ ke $\mathrm{y}_{\mathrm{n}}$.

- Debit yang melewati bendung (Q) Thompson.

- $\mathrm{tp}_{1}=$ tinggi pasir yang tidak tergerus.

- $\operatorname{tp}_{2}=$ tinggi pasir di bawah aliran hilir.

- $\mathrm{ds}=$ kedalaman penggerusan yang terjadi akibat aliran suatu debit tertentu.

\section{Pengamanan Gerusan Lokal Akibat dihilir bendung.}

Blok beton terkunci merupakan inovasi teknologi yang relatif baru di bidang pengamanan gerusan lokal akibat aliran sungai. Gerusan lokal merupakan suatu fenomena yang biasa terjadi di hilir bangunan yang dibangun pada aliran sungai. Gejala gerusan lokal seringkali tampak terjadi di hilir peredam energi. Dampak dari gerusan lokal harus diwaspadai karena dapat berpengaruh pada penurunan stabilitas keamanan bangunan air. Proses terjadinya gerusan lokal biasanya dipicu oleh tertahannya angkutan sedimen yang dibawa bersama aliran oleh struktur bangunan dan peningkatan turbulensi aliran akibat gangguan suatu struktur. Untuk menyeimbangkan angkutan 
sedimen sesuai dengan kapasitasnya, maka aliran akan menggerus dasar sungai di hilir struktur, sehingga terjadi penurunan dasar sungai yang cukup dalam di hilir struktur dan dikenal sebagai gerusan lokal. Apabila penurunan dasar ini berlangsung pada suatu ruas sungai dengan panjang tertentu, maka hal ini bukan lagi merupakan fenomena gerusan lokal, melainkan dikenal sebagai gejala degradasi dasar sungai.

Pengamanan bangunan keairan terhadap gerusan lokal maupun degradasi dasar sungai dapat dilakukan dengan menggunakan beberapa cara dengan tujuan untuk mencegah dan mengurangi dalam gerusan lokal yang terjadi agar kestabilan bangunan tetap terjaga. Cara penanggulangan gerusan lokal yang sudah biasa dilakukan selama ini adalah dengan penyesuaian desain bangunan peredam energi dan pembuatan bang unan pengendali dasar sungai (bottom controler) yang terbuat dari pasangan batu, bronjong atau beton bertulang dengan biaya yangcukup besar. Sedangkan pemanfaatan blok beton terkunci yang biasa digunakan untuk menahan abrasi akibat ombak di daerah pantai belum biasa digunakan.

Tantangan lapangan terkait dengan masalah gerusan lokal dan degradasi dasar sungai adalah keterbatasan waktu pelaksanaan, kecenderungan morfologi sungai yang selalu berubah dan data lapangan yang terbatas. Berkaitan dengan hal ini, struktur blok beton terkunci yang modular, saling terkunci, mudah diterapkan di lapangan dengan metoda dan alat bantu yang tidak terlalu rumit dapat digunakan sebagai alternatif pengendalian gerusan lokal dan degradasi dasar di sungai.

\section{HASIL}

\section{Perhitungan Debit}

Perhitungan debit berdasarkan debit (Q) hasil pengamatan elevasi muka air yang melimpas pada alat ukur segitiga Thompson. Besarnya debit (Q) berdasarkan rumus : $\quad \mathrm{Q}=1,38 \mathrm{H}_{\mathrm{t}}^{5 / 2}$

dimana :

$$
\begin{aligned}
\mathrm{H}_{\mathrm{t}}= & \text { Kedalaman aliran air yang } \\
& \text { melewati alat ukur segitiga } \\
& \text { Thompson }(\mathrm{m}) .
\end{aligned}
$$

Untuk debit per satuan lebar (q) berdasarkan rumus : $\quad \mathrm{q}=\mathrm{Q} / \mathrm{B}$

dimana :

$\mathrm{Q}=$ Debit Thompson .

\begin{tabular}{|c|c|c|c|c|c|c|c|c|}
\hline $\begin{array}{l}\text { No. } \\
\text { Test }\end{array}$ & $\begin{array}{c}\text { EL.H } H_{d} \\
(m)\end{array}$ & $\begin{array}{l}\text { El. } y_{n} \\
(m)\end{array}$ & $\begin{array}{l}y_{n} \\
(m)\end{array}$ & $\begin{array}{l}\Delta H \\
(\mathrm{~m})\end{array}$ & $\begin{array}{c}q \\
\left(\mathrm{~m}^{3} / \mathrm{dt} / \mathrm{m}\right)\end{array}$ & $\begin{array}{c}\mathbf{q} / \sqrt{ } \mathbf{g} \cdot \Delta \mathbf{H}^{3} \\
(-)\end{array}$ & $\begin{array}{l}d_{s} \\
(m)\end{array}$ & $\begin{array}{c}d s / y_{n} \\
(-)\end{array}$ \\
\hline 1 & 0.3320 & 0.1570 & 0.0320 & 0.2750 & 0.0068 & 0.0150 & 0.0602 & 1.8813 \\
\hline 2 & 0.3350 & 0.1666 & 0.0410 & 0.2690 & 0.0079 & 0.0181 & 0.0816 & 1.9902 \\
\hline 3 & 0.3410 & 0.1744 & 0.0494 & 0.2666 & 0.0122 & 0.0283 & 0.1021 & 2.0668 \\
\hline 4 & 0.3520 & 0.1844 & 0.0594 & 0.2676 & 0.0183 & 0.0422 & 0.1265 & 2.1296 \\
\hline 5 & 0.3550 & 0.1893 & 0.0643 & 0.2657 & 0.0215 & 0.0501 & 0.1385 & 2.1540 \\
\hline 6 & 0.3645 & 0.1951 & 0.0701 & 0.2694 & 0.0266 & 0.0607 & 0.1525 & 2.1755 \\
\hline 7 & 0.3670 & 0.2061 & 0.0811 & 0.2609 & 0.0296 & 0.0709 & 0.1780 & 2.1948 \\
\hline 8 & 0.3750 & 0.2330 & 0.1080 & 0.2420 & 0.0346 & 0.0928 & 0.2450 & 2.2685 \\
\hline
\end{tabular}

$\mathrm{B}=$ Lebar saluran percobaan.

Tabel 1. Perhitungan faktor aliran terhadap dalamnya penggerusan per kedalaman hilir. 
Tabel 2. Perbandingan dalamnya penggeru san model dengan formula-formula para ahli terhadap pola debit pada bendung mercu bulat peredam energi Bucket tunggal, berjari-jari, $\mathrm{R}$ $=6 \mathrm{~cm}$.

\begin{tabular}{ccc}
\hline $\mathbf{q} /\left(\mathbf{g} . \Delta \mathbf{H}^{\mathbf{3}}\right)^{\mathbf{0 . 5}}$ & \multicolumn{2}{c}{$\mathbf{d s} / \Delta \mathbf{H}$} \\
\cline { 2 - 3 }$(-)$ & Model & Lacey \\
\hline 0.0150 & 0.2189 & 0.8712 \\
0.0176 & 0.3033 & 0.9815 \\
0.0278 & 0.3830 & 1.3383 \\
0.0420 & 0.4727 & 1.7732 \\
0.0522 & 0.5213 & 1.9942 \\
0.0658 & 0.5661 & 2.2938 \\
0.0765 & 0.6823 & 2.5241 \\
0.0986 & 1.0124 & 2.9565 \\
\hline
\end{tabular}

Berikut ini adalah grafik-grafik hasil pengamatan pada bendung mercu bulat dengan peredam energi tipe Bucket tunggal berjari-jari $\mathrm{R}=6 \mathrm{~cm}$

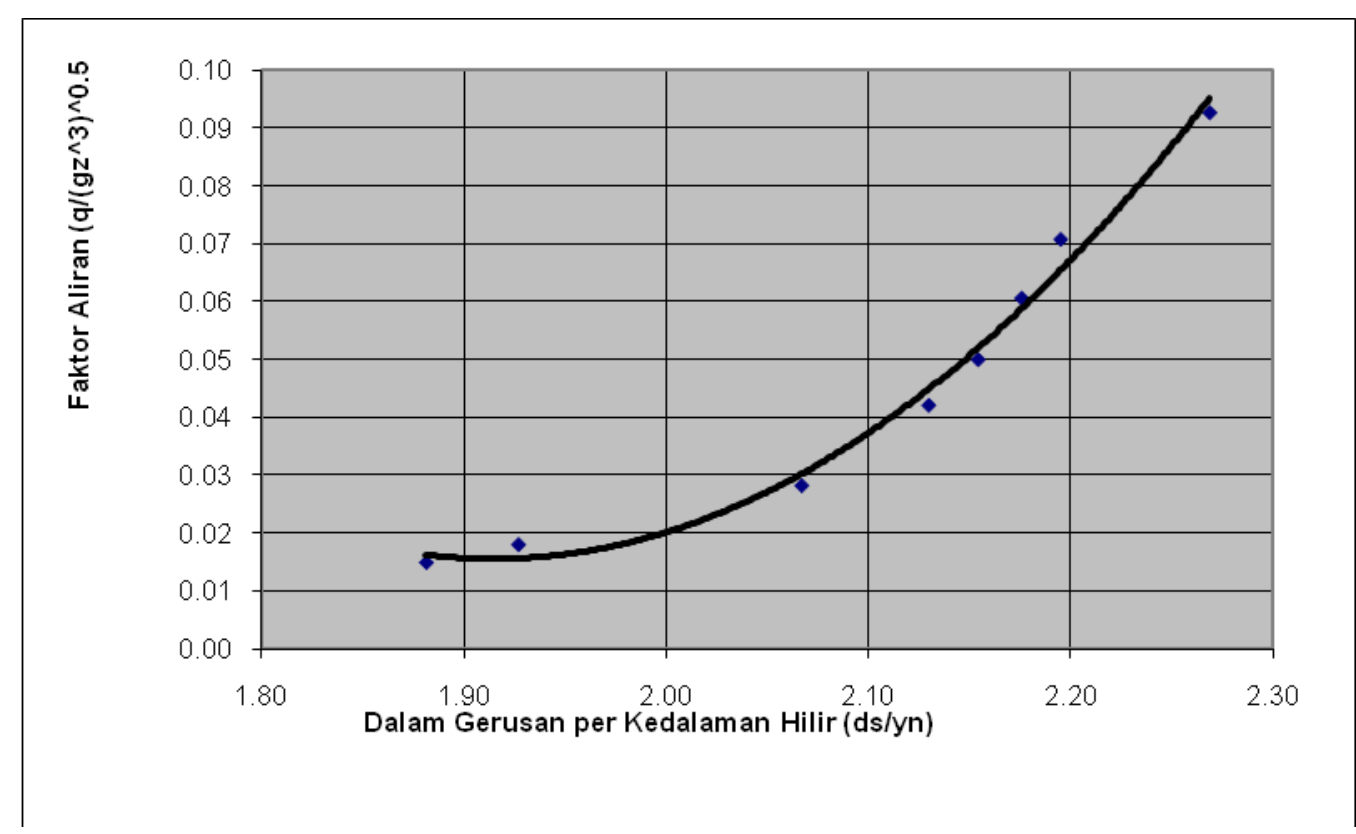

Gambar 2. Grafik hubungan dalamnya penggerusan per kedalaman air hilir dengan faktor aliran. 


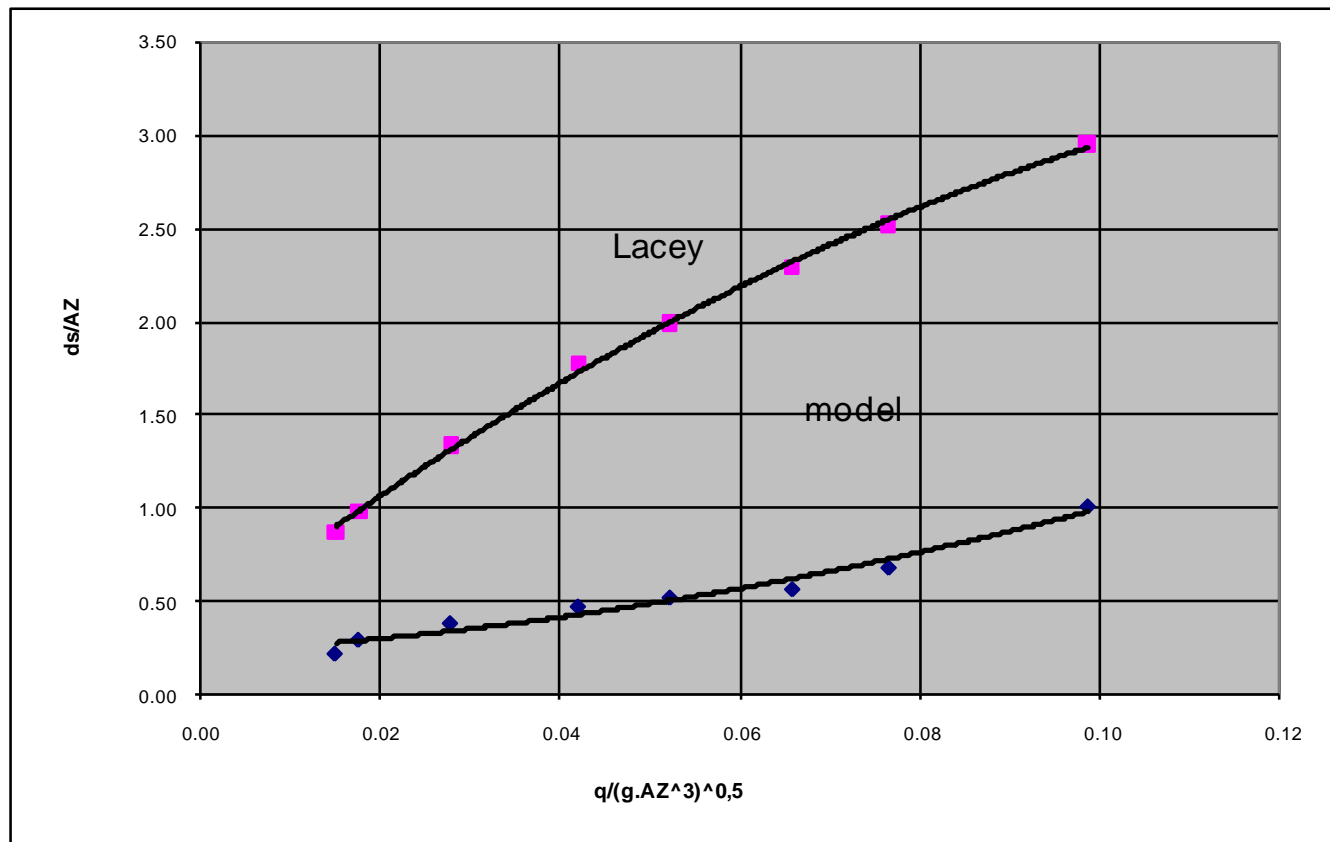

Gambar 3. Grafik perbandingan kedalaman penggerusan antara hasil uji model I dengan formula Lacey.

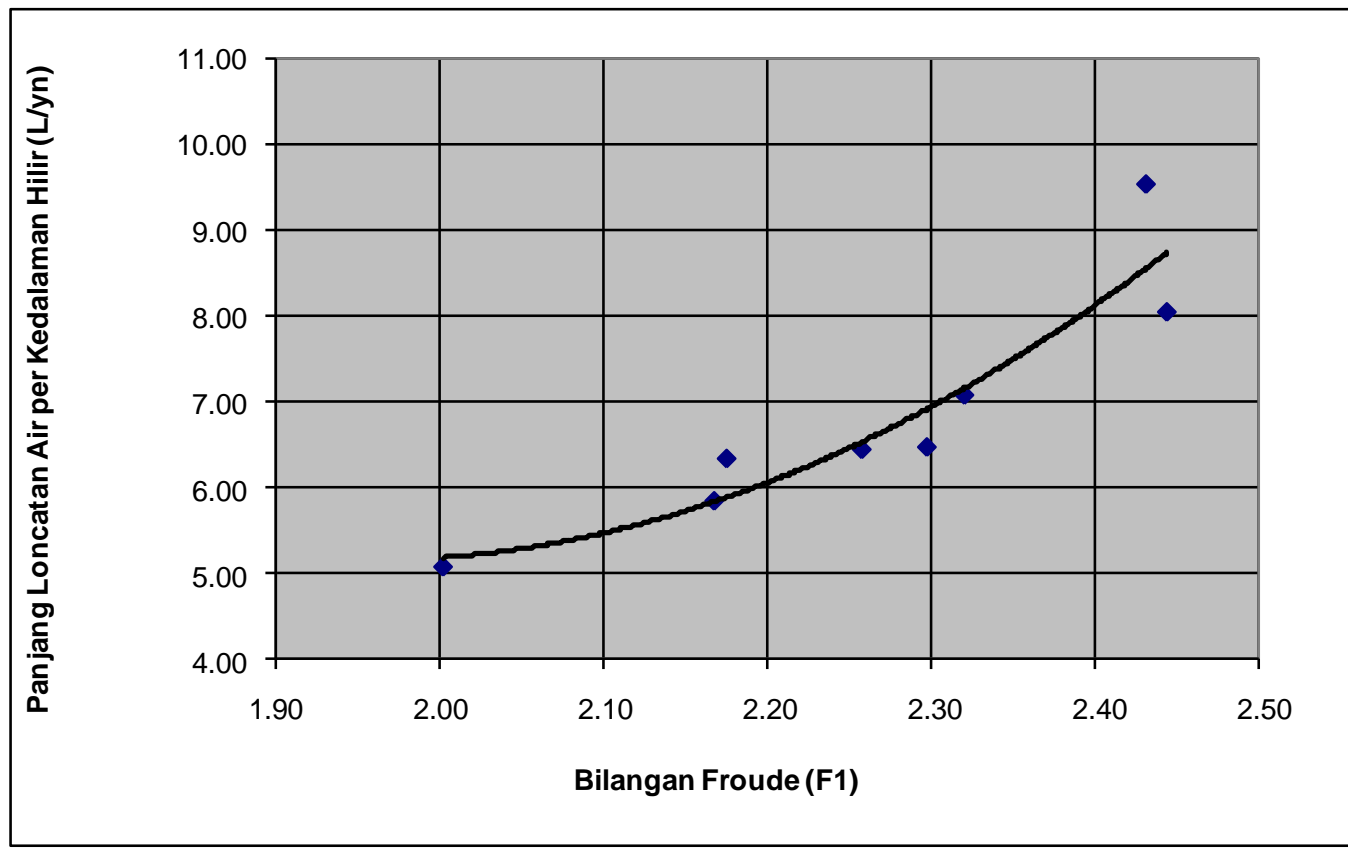

Gambar 4. Grafik hubungan Bilangan Froude dengan panjang loncatan air per kedalaman air hilir. 


\section{PEMBAHASAN}

\section{Analisa Grafik Pada Bendung Mercu Bulat Dengan Peredam Energi Tipe Bucket Tunggal}

Dari hasil analisis data hasil uji model seri I pada saluran terbuka dengan lebar $0,40 \mathrm{~m}$ pada kondisi dasar saluran datar yang sudah diperoleh dalam tabel terlampir dan kemudian hasilnya di plot dalam serangkaian grafik. Dalam hal ini umumnya berupa grafik-grafik karakteristik dengan skala absis dan skala ordinat tanpa satuan (Non-dimensional).

Hubungan antara dalamnya pengge rusan per kedalaman air hilir terhadap faktor aliran

Dari gambar 2 menunjukan dalamnya penggerusan per kedalaman air hilir $\left(\mathrm{d}_{\mathrm{s}} / \mathrm{y}_{\mathrm{n}}\right)$ terbentuk oleh faktor aliran $\left(\mathrm{q} /\left(\mathrm{g} \cdot \Delta \mathrm{H}^{3}\right)^{0,5}\right)$. Dari grafik ini dapat menunjukan karakteristik pentingnya variabel-variabel hubungan antara kedalaman penggerusan, kedalaman air hilir, pola debit, dan beda elevasi muka air hulu dan hilir bangunan hidraulik. Grafik karakteristik tersebut menunjukan kedalaman gerusan per kedalaman air hilir cendrung naik secara pendekatan persamaan polinomial terhadap faktor aliran. Kedalaman gerusan per kedalaman hilir terbesar adalah 2,27 terjadi pada pola debit

terbesar $\left(\mathrm{q}=0,0346 \mathrm{~m}^{3} / \mathrm{det} / \mathrm{m}\right)$ dengan dalam gerusan sebesar $0,025 \mathrm{~m}$, beda elevasi muka air hulu dan hilir adalah 2,45 cm serta kedalaman air normal hilir 5,80 $\mathrm{cm}$. Hal ini secara logika menjabarkan untuk suatu bentuk bangunan hidraulik tertentu dengan ukuran tertentu dengan penambahan pola debit aliran untuk dasar hilirnya akan tergerus bertambah dalam walaupun terjadi pengurangan energi yang lebih besar juga karena benturan antara partikel terjunan air dengan kedalaman air di hilirnya yang bertambah besar juga.

\section{Perbandingan Dalamnya Penggerusan Dari Hasil Uji Model Terhadap Pemakaian Formula Lacey.}

Dari gambar 3 menunjukan perbandingan hasil uji model dan penggunaan formulaformula dari para ahli terhadap dalamnya penggerusan $\left(d_{s}\right)$ oleh berbagai pola debit per satuan lebar (q), kedalaman terjunan atau beda elevasi muka air hulu dan hilir, dan bahan dasar saluran dengan gradasi tertentu. Dari grafik yang dihasilkan baik menurut uji model dan penggunaan formula-formula oleh para ahli di luar negeri menunjukan bahwa kedalaman gerusan per kedalaman terjun mempunyai kecendrungan naik dengan pendekatan persamaan polinomial terhadap faktor aliran. Dari hasil uji model dan formulaformula oleh para ahli menunjukan kedalaman gerusan per kedalaman terjunan yang berbeda-beda terhadap faktor aliran, bahkan mempunyai selisih perbedaan yang cukup besar. Sebagai pemisalan, kedalaman gerusan per kedalaman terjunan $(\mathrm{ds} / \Delta \mathrm{H})$ untuk faktor aliran terbesar $\left(\mathrm{q} /\left(\mathrm{g} . \Delta \mathrm{H}^{3}\right)^{0,5}=\right.$ 0,099) pada uji model : 1,01, Lacey : 2,96, menunjukan bahwa dengan menggunakan formula-formula yang telah ada, mempunyai deviasi terhadap hasil uji model.

Panjang Loncatan Hidraulik per Kedalaman Air Hilir Terhadap Bilangan Froude

panjang loncatan hidraulik per kedalaman air hilir $\left(\mathrm{L} / \mathrm{y}_{\mathrm{n}}\right)$ terbentuk oleh Bilangan Froude $\left(\mathrm{F}_{1}=2,00-2,43\right)$ terjadi $100 \%$ loncatan lemah. Panjang loncatan hidraulik dan kedalaman air hilir merupakan faktor yang sangat mempengaruhi lokasi penggerusan terdalam dan pola gerusan. Hasil pengamatan terhadap gerusan terdalam (ds) yang terjadi di belakang Endsill yaitu berjarak $50 \mathrm{~cm}$ sedalam 24,50 $\mathrm{cm}$ untuk bagian tengah, berjarak $44 \mathrm{~cm}$ sedalam $24,50 \mathrm{~cm}$ untuk bagian kiri, berjarak $43 \mathrm{~cm}$ sedalam 27,50 $\mathrm{cm}$ untuk 
bagian kanan yang terjadi pada pada debit maksimum $\mathrm{q}=0,0346 \mathrm{~m}^{3} / \mathrm{det} / \mathrm{m}$.

Grafik karakteristiknya menunjukan kecendrungan panjang loncatan hidraulik per kedalaman hilir naik dengan pendekatan persamaan polinomial terhadap Bilangan Froude. Panjang loncatan air per kedalaman hilir terbesar adalah 9,53 pada pola debit terkecil $\left(\mathrm{q}=0,0068 \mathrm{~m}^{3} / \mathrm{det} / \mathrm{m}\right)$ atau Bilangan Froude terbesar $\left(\mathrm{F}_{1}=2,43\right)$. Hal ini menunjukan bahwa semakin kecil pola debit yang melimpas (Bilangan Froude semakin besar) rasio panjang loncatan terhadap kedalaman normal di hilirnya akan relatif bertambah besar.

\section{SIMPULAN}

1. Semakin kecil kedalaman penggerusan, pondasi di kaki bendung bisa dibuat lebih dangkal, menambah faktor keamanan serta umur layan dari bendung.

Dari pola gerusan (besarnya kedalaman dan panjang penggerusan) dapat pula dipastikan bahwa volume material dasar sungai yang hanyut ke hilir aliran pada mode sehingga perubahan dinamik morfologi di hilir bendungnya juga lebih besar sehubungan dengan proses degradasi dan agradasi dasar sungai.

2. Perbandingan antara hasil uji model dengan rumus-rumus untuk meramalkan kedalaman penggerusan setempat dari para ahli (Lacey), dengan pola debit dan diameter butir dasar yang diambil sama, menunjukan adanya deviasi (penyimpangan. Dalam hal ini menunjukan bahwa penggunaan rumusrumus untuk meramalkan kedalaman penggerusan mempunyai validasi yang berbeda-beda dalam penggunaanya dan terbukti bahwa melalui hasil uji model fisik pada keadaan setempat lebih menjamin keakuratan hasil.

3. Untuk penanggulangan gerusan dihilir bendung biasanya digunakan batubatu besar, blok-blok beton dan yang terbaru dengan menggunakan blok beton terkunci. Blok beton terkunci memiliki prinsip kerja dapat meningkatkan stabilitas terhadap gaya seret bergantung kepada arah lengan momen guling yang mana blok beton tersebut dapat berguling. Keadaan saling terkait blok beton terkunci mampu menahan gaya seret

\section{DAFTAR PUSTAKA}

Astuti, K.A dan Widyaningtias, 2006, Gerusan yang Terjadi di Sekitar Abutment Dinding Vertikal Tanpa Sayap (Kajian Laboratorium), Tugas Akhir, Departemen Teknik Sipil, Fakultas Teknik Sipil dan Perencanaan, Institut Teknologi Bandung.

Bharbhuiya, 2004, Local Scour at Abutment:A Review, Sadhana, 29 (5): 449-476.

Froehlich, D.C., 1989, Local Scour at Bridge Abutments, San Francisco, California:

Proceedings, ASCE, National Hydraulics Conference, 922-927.

Kandasamy, J.K and Melville, B.W., 1998, Maximum Local Scour Depth at Bridge Piers and Abutments, Journal Hydraulic Research, IAHR, 36(2), 183-198.

Laursen, E.M., 1960, Scour at Bridge Crossings, Journal Hydraulic Division, ASCE, 86: 39-54.

Melville, B.W., 1997, Pier and Abutments Scour: Integrated Approach, Journal of Hydraulic Engineering, 123 (2), 125-136.

Priyantoro, D.2007. Pengaruh Pemasangan Gigi Benturan (BaffleBlock) Terhadap Panjang Lantai PeredamEnergi Kolam Olakan Datar Tipe IV. Hasil Penelitian Malang. 
Richardson, E.V., Harrison, L.J., and Davis, S.R., 1991, Evaluating Scour at Bridges: Hydraulic Engineering Circular No. 18, Publication No. FHWA-IP-90-017, Office of Research and Development.

Richardson, J.R. and Richardson, E.V., 1993, Discussion of Local Scour at Bridge Abutments, By B.W. Melville, Journal HydraulicEngineering, ASCE, 119(9), 1069-1071.

Richardson, E.V. and Davis, S.R. 1995, Evaluating Scour at Bridges, Hydraulic Engineering Circular No. 18 (HEC-18), Publication No. FHWA-IP-90-017, Third Edition, Federal Highway Administration.

Van Rijn, L.C, 1984, Sediment Transport, Part II: Suspended Load Transport, Journal of Hydraulic Engineering, ASCE, 110 (11), 1613-1641. 